\title{
VALUATION OF RUBBER WASTE AND DUNE SAND: MORTAR FOR CONSTRUCTION AND ENVIRONMENTAL PROTECTION
}

\author{
Assia Aidoud ${ }^{1, *}$, Messaouda Bencheick', Salima Boukour ${ }^{2}$ \\ 'University 8 may 1945 of Guelma \& Civil Engineering and Hydraulics Laboratory, Guelma, Algeria \\ ${ }^{2}$ Civil Engineering and Hydraulic Laboratory, University Center of Abdelhafid Boussouf Mila, Mila, Algeria \\ *Corresponding author: E-mail: assia_aidoud76@yahoo.fr
}

\begin{abstract}
The main objective of this study is the recovery of dune sands and rubber waste (powders). The latter constitutes a potential source of several environmental and economic problems.

The objective of this present work is to examine the ability to use dune sand for the preparation of mortars with sufficient physico-mechanical properties to allow them to be used in various building construction applications. The formulation of the mixtures is based on replacing dune sand with powders, at different weight contents: $10 \%$, $20 \%$, and $30 \%$. The quantity of cement is set at $450 \mathrm{~g}$. The results obtained show in the first place that the particle size of the mixture tends to be spread out with a remarkable increase in the fineness modulus, and in the second place the density of the mixture decreases by $6.5 \%$ (for the apparent) and by $10 \%$ (for the absolute), which means the calculation of loads for the resulting mortar must decrease. Porosity has decreased to $20 \%$ and absorption has increased to $30 \%$. The strengths have decreased over $40 \%$ for compressive strength and over $30 \%$ for tensile strength, with an improvement in the relationship between the two strengths.
\end{abstract}

Key words: Mortar, dune sand, rubber, porosity, absorption, strength

\section{Introduction}

In Algeria, the quality control bodies for structural concrete require that the aggregates are made from alluvial or quarry sands and crushed gravel. However, some projects, especially those carried out in the south, are far from the deposits exploited for the crushing of aggregates (more than $600 \mathrm{~km}$ ). The energy expended for crushing and the budget reserved for the transport of crushed aggregates considerably amplifies the cost of producing one $\mathrm{m}^{3}$ of concrete [1].

Southern Algeria has significant renewable natural reserves of dune sand, characterized by a fine grain size but with a chemical and mineralogical composition rich in silicon [2]. This paradox has prompted several scientists to search for a formulation devoid of coarse aggregate and therefore composed essentially of cement, filler, micro filler, sand and water [3-7].
Several studies have been carried out on mortars in order to know their formulations and to determine their characteristics and their rheological behavior. These studies have been able to prove that dune sand-based mortar could advantageously replace ordinary mortar in certain sectors of building and public works [8].

Waste from different sources is the cause of various environmental problems related to its storage and its increasing quantities. In addition, traditional building materials of natural origin are faced with exhaustion over time. It is therefore important to think about the development of composite materials with artificial aggregates, or those that are recycled from industrial and agricultural waste. This type of material meets economic and environmental requirements [9]. Indeed, the operation of industrial vehicles of different categories generates significant quantities of 
tire waste, which does not benefit from any recovery action [10-11]. In Algeria, strong pressure on the environment has been recorded, especially with regard to waste from means of transport, specifically tires [12]. All over the world, used tire waste represents a potential source of major environmental and economic problems [10]. According to recent statistics, the annual world production of waste tires is estimated at 17 million tonnes. The latest global initiatives to reduce air pollution require the use of clean methods of waste disposal in order to protect the environment from its harmful effects [10].

The construction sector has been using waste and by-products for several years as secondary raw material for the development of new types of materials that have specific or improved properties compared to conventional materials. This alternative makes it possible on the one hand to respond to the concern for saving natural resources in aggregates, and on the other hand to alleviate economic and environmental constraints through the reuse and recycling of waste [13].

The objective of this work is the recovery of sand from dunes (DS) and the use of waste powdered tires in order to exploit them for the manufacture of mortar suitable for use in the construction sector. In our study we try to develop and characterize a rubberized sand mortar. This development is made by the addition of rubber content (RC). The formulation of the mixtures adopted is based on the mass substitution of dune sand by different percentages of rubber $(10 \%, 20 \%$, and $30 \%)$. The quantity of cement is fixed at $450 \mathrm{~g}$ (based on the composition of a normalized mortar).

\section{Experimental details}

The materials used in this work for the preparation of the mixtures and the making of the various mortars are of local origin (Figure 1); their chemical compositions and their physical properties are shown in Table 1 and Table 2 respectively.

A control sand mortar, and three mortars composed of cement and by different percentages of (RC) (10\%, $20 \%$ and $30 \%)$ and dune sand, respectively (Figure 2 shows the mixes at different substitutions and Figure 3 shows the result for each mix) for each composition (Table 3) made the object of this comparative study. The tests concerned the determination

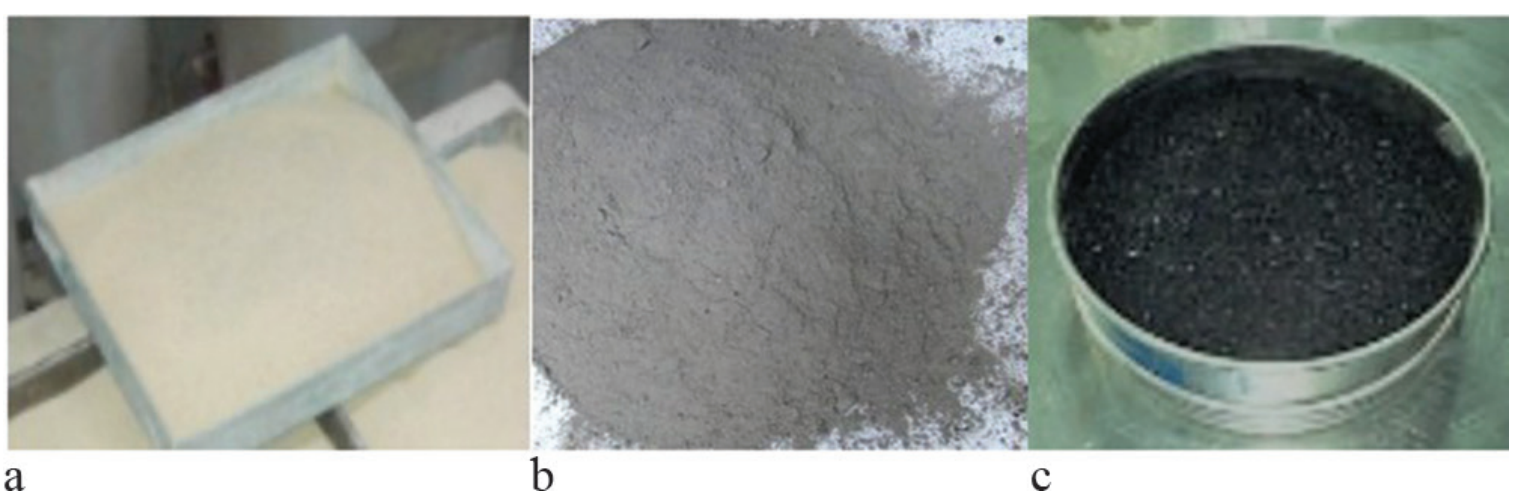

Figure 1: The materials used, a) Dune sand, b) Cement, c) Rubber powder.

Table 1: Chemical compositions of cement and dune sand

\begin{tabular}{lccccccccc} 
& $\mathbf{C a O}$ & $\mathbf{S i O}_{2}$ & $\mathbf{A l}_{\mathbf{2}} \mathbf{O}_{\mathbf{3}}$ & $\mathbf{F e}_{\mathbf{2}} \mathbf{O}_{3}$ & $\mathbf{M g O}$ & $\mathbf{K}_{\mathbf{2}} \mathbf{O}$ & $\mathbf{N a}_{\mathbf{2}} \mathbf{O}$ & $\mathbf{S O}_{\mathbf{3}}$ & LoI $^{*}$ \\
\hline Cement & 58.6 & 24.92 & 6.58 & 3.65 & 1.21 & 0.85 & 0.08 & 2.17 & 1.7 \\
Dune Sand & 1.63 & 90.46 & 1.38 & 1.92 & 0.39 & 0.22 & 0.00 & 0.2 & 2.56 \\
\hline * Loss on Innition & & &
\end{tabular}


Table 2: General material properties

\begin{tabular}{lcccc} 
& Unit & Dune Sand & Cement & RC \\
\hline Finess modulus & $(\%)$ & 1.837 & - & 3.92 \\
Sand equivalent (visual) & $(\%)$ & 99.56 & - & - \\
Sand equivalent (piston) & $(\%)$ & 85.97 & - & - \\
Apparent density & $\left(\mathrm{g} / \mathrm{cm}^{3}\right)$ & 1.46 & 1.09 & 0.40 \\
Absolute density & $\left(\mathrm{g} / \mathrm{cm}^{3}\right)$ & 2.11 & 3.11 & 0.94 \\
BSS & $\left(\mathrm{cm}^{2} / \mathrm{g}\right)$ & - & 3371 & - \\
\hline
\end{tabular}

*Blain Specific Surface

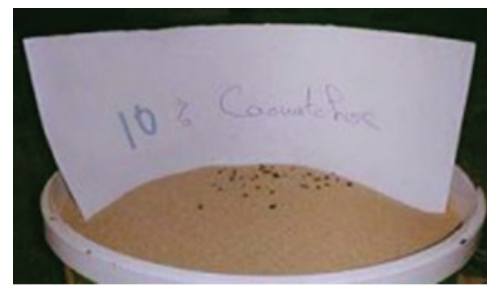

a

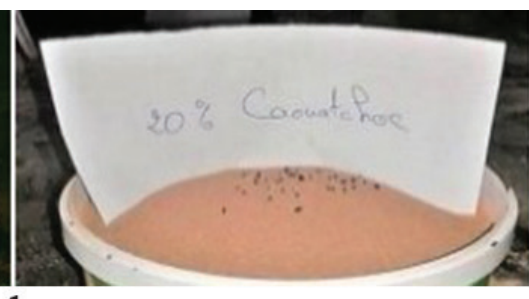

b

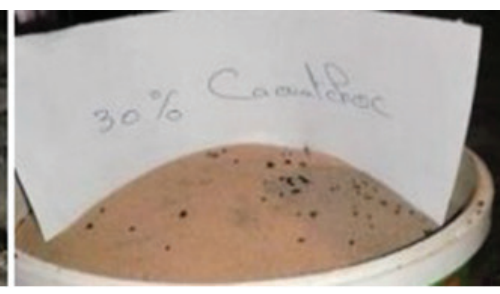

c

Figure 2: The three mixtures of DS with the three substitutions: a) 10\%, b) $20 \%$ and c) $30 \%$.

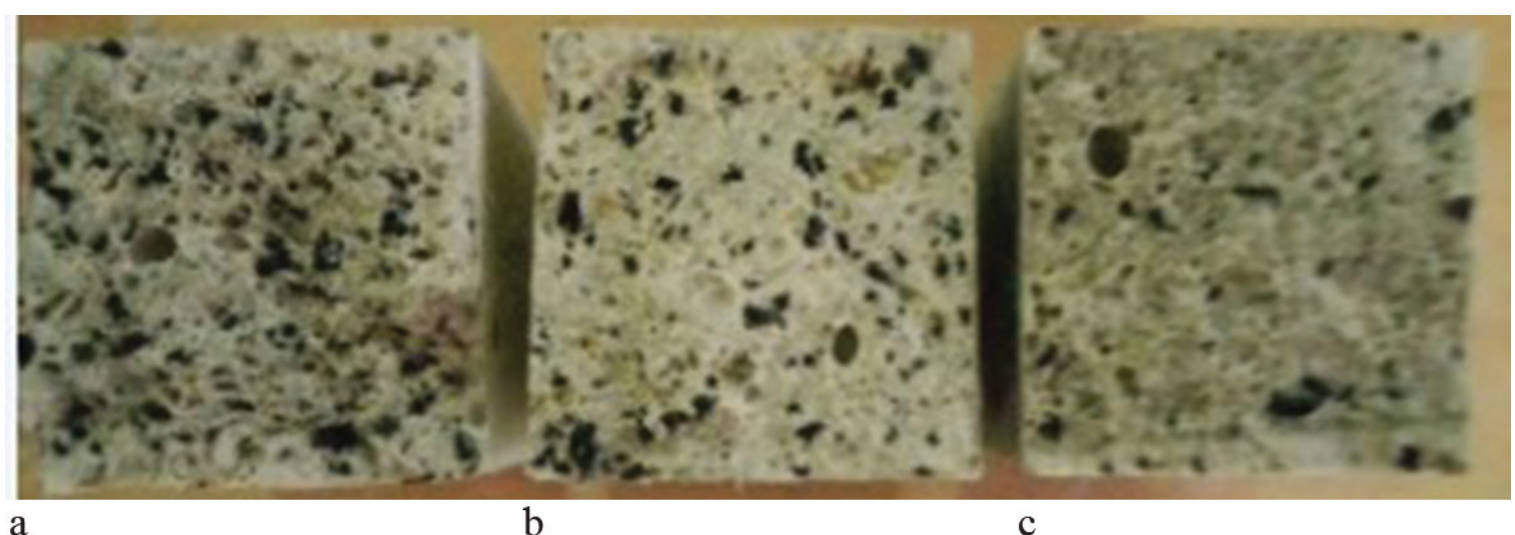

a

b

c

Figure 3: The three mortars made with DS mixes with three substitutions: a) $30 \%$, b) $20 \%$ and c) $10 \%$.

of some physico-mechanical properties of the mortars (porosity, absorption, densities, compressive strength, tensile strength). All the tests were carried out on prismatic specimens $(4 \mathrm{~cm}$ $\mathrm{x} 4 \mathrm{~cm} \times 16 \mathrm{~cm}$ ).

The compression (Figure 4) and tensile tests (by three-point bending) (Figure 5) were carried out by a universal digital CONTROLS brand mechanical resistance testing machine with a capacity of $50 \mathrm{kN}$, at controlled load and displacement. The measurements of the physical properties were carried out by a hydrostatic balance precision of $0.01 \mathrm{~g}$.

\section{Effect of rubber on the physico-mechanical properties of the mortar}

The various results are grouped together in the table and illustrated by the figures below. 
Table 3. Composition of the mortars studied

\begin{tabular}{lcccc} 
Rubber content (\%) & $\mathbf{0}$ & $\mathbf{1 0}$ & $\mathbf{2 0}$ & $\mathbf{3 0}$ \\
\hline Dune Sand (g) & 1350 & 1215 & 1080 & 945 \\
Cement (g) & 450 & 450 & 450 & 450 \\
Water (g) & 450 & 450 & 450 & 450 \\
Rubber Caoutchouc (g) & 0 & 60.14 & 120.28 & 180.42 \\
Water/Cement & 1 & 1 & 1 & 1 \\
\hline
\end{tabular}

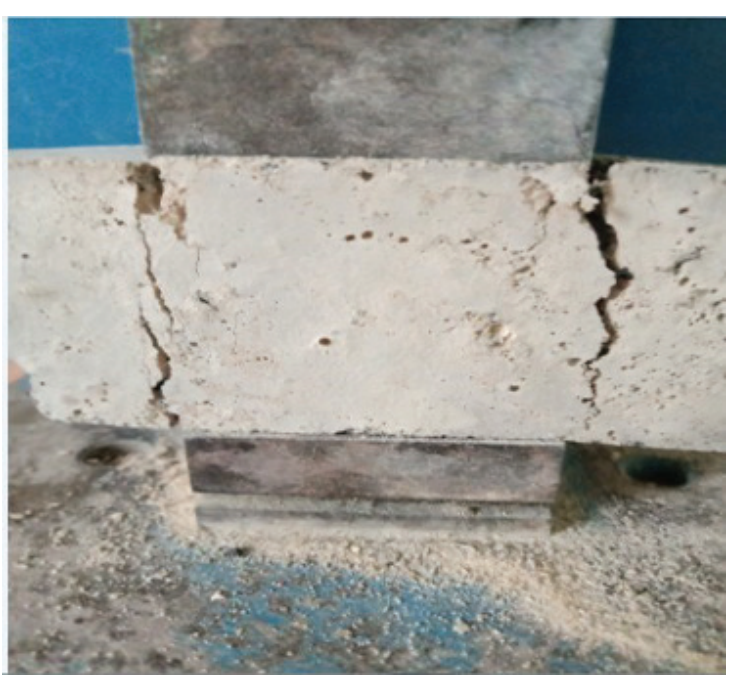

Figure 4: The compression test.

\section{Effect of rubber on the physical properties of the mortar}

With each increase in the content of substituted rubber in the sand, the grain size curve of the mixture tends to spread out (Figure 6).

The fineness modulus of the mixtures increases with the increase in the content of rubber (Figure 7).

For a mixture of DS substituted with $10 \%$ rubber, the fineness modulus increased by $5 \%$ compared to the fineness modulus of the control DS, but despite the substitution of the DS at $20 \%$, a slight increase of $7 \%$ was noticed of the fineness modulus relative to the fineness modulus of the control DS. On the other hand the increase was very remarkable (20\%) for the mixture of DS substituted for $30 \%$ of the rubber.

It can also be seen that despite these increases in fineness moduli, our mixtures still remain within the fine sands interval. But what caught our attention that the finesse modulus jumped between the two ends of this interval.

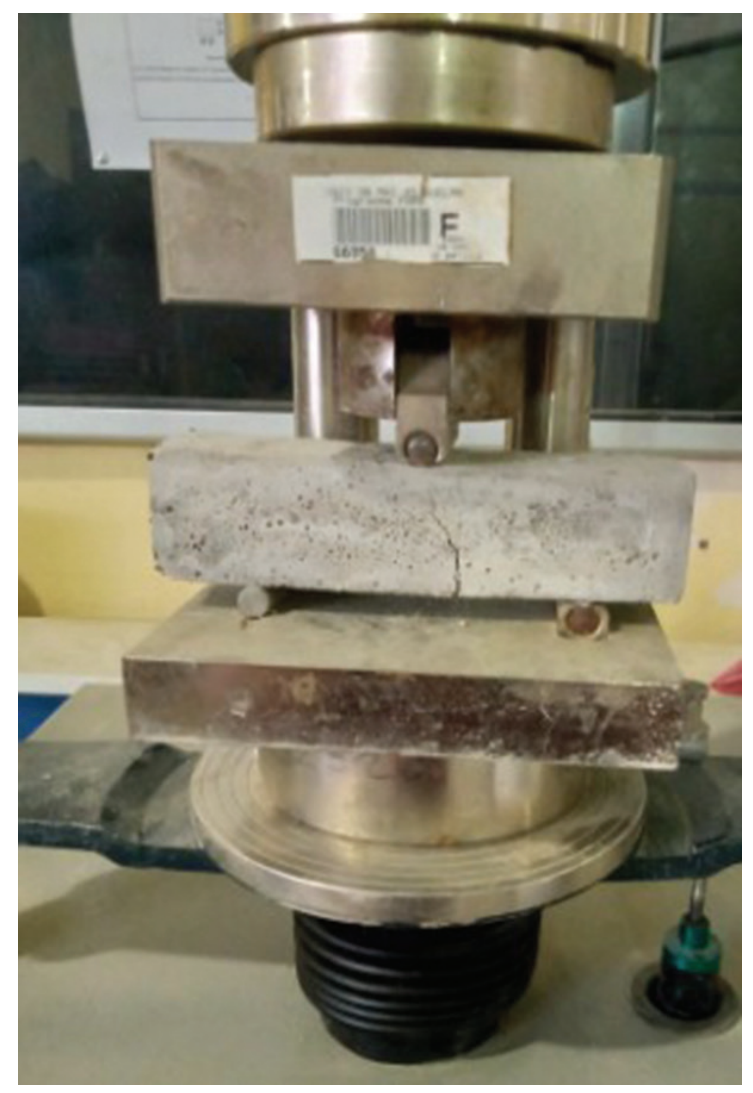

Figure 5: The three-point flexural tensile test.

All DS-based mortars with RC substitutions of $10 \%, 20 \%$, and $30 \%$ experience decreases in their densities either wet or dry (Figure 8) compared to the control mortar, of the order of $2.86 \%, 5.71 \%$, and $6.86 \%$ and $0.64 \%, 3.85 \%$, and $5.13 \%$ respectively. This is particularly useful in rehabilitation works and the lightening of structures. These decreases are less important than those found by Benazzouk et al. [13] and by Boukour [14].

According to Figure 8, the wet density of the mortar varies according to the rubber 
Table 4: Effect of rubber on the physico-mechanical properties of the mortars studied

\begin{tabular}{lcccc} 
Rubber content (\%) & $\mathbf{0}$ & $\mathbf{1 0}$ & $\mathbf{2 0}$ & $\mathbf{3 0}$ \\
\hline Fineness modulus (\%) & $1.837 \pm 0,027$ & $1.93 \pm 0,043$ & $1.98 \pm 0,056$ & $2.20 \pm 0,068$ \\
Wet density $\left(\mathrm{g} / \mathrm{cm}^{3}\right)$ & $1.75 \pm 0.026$ & $1.7 \pm 0.016$ & $1.65 \pm 0.004$ & $1.63 \pm 0.013$ \\
Dry density $\left(\mathrm{g} / \mathrm{cm}^{3}\right)$ & $1.56 \pm 0.045$ & $1.55 \pm 0.023$ & $1.5 \pm 0.006$ & $1.48 \pm 0.01$ \\
Absorption (\%) & $12.1 \pm 1.85$ & $9.81 \pm 0.62$ & $9.77 \pm 0.08$ & $10.64 \pm 0.12$ \\
Porosity (\%) & $18.86 \pm 2.39$ & $15.21 \pm 0.73$ & $14.69 \pm 0.09$ & $15.71 \pm 0.27$ \\
Tensile strength (MPa) & $5,47 \pm 1.11$ & $4.95 \pm 0.31$ & $4,71 \pm 1.41$ & $3,36 \pm 0.61$ \\
Compressive strength $(\mathrm{MPa})$ & $26,51 \pm 2.46$ & $18,44 \pm 0.29$ & $17,33 \pm 0.77$ & $14,01 \pm 1.00$ \\
\hline
\end{tabular}

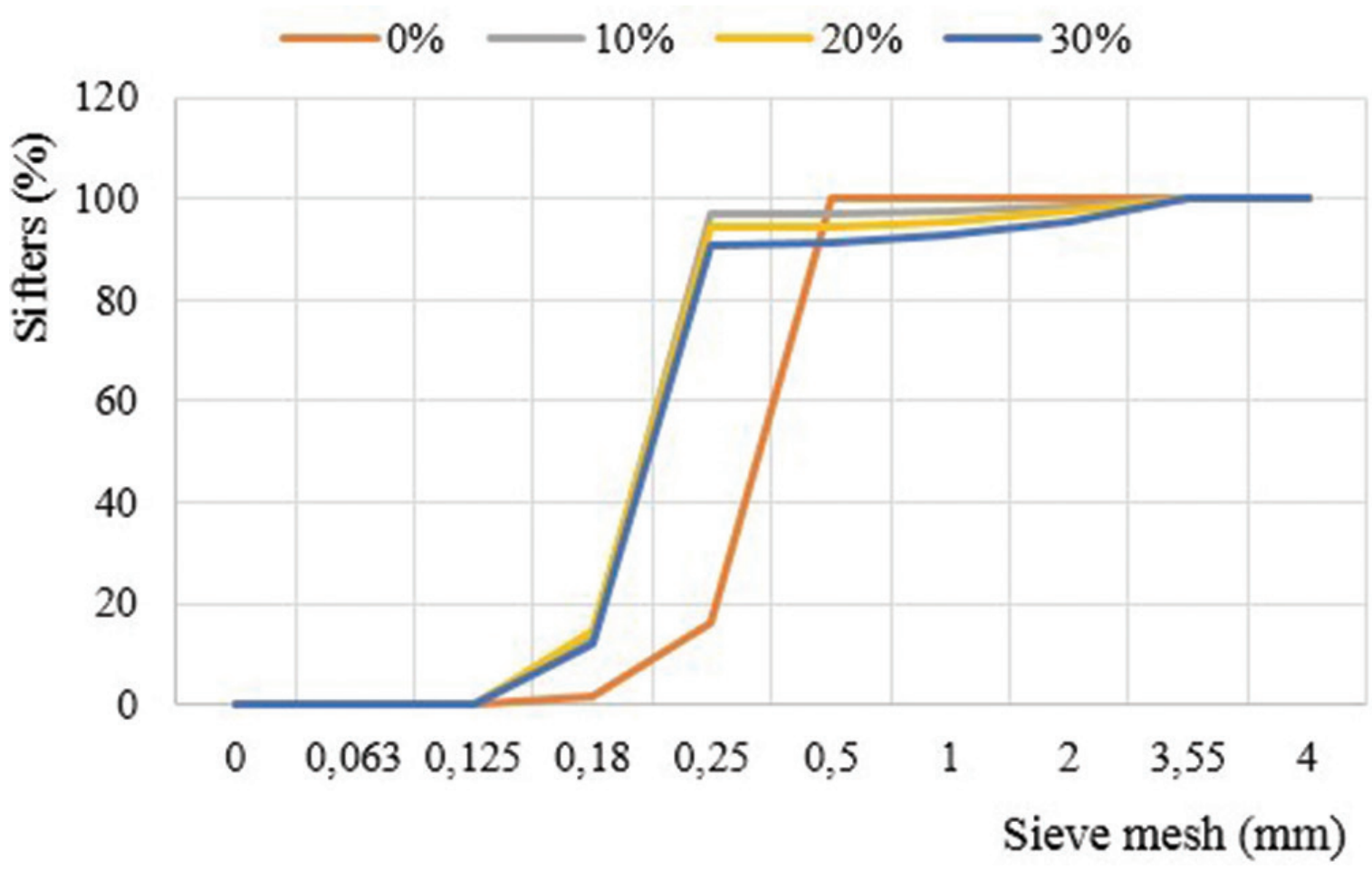

Figure 6: Particle size curves of the mixtures as a function of the rubber content.

content, according to the expression: $\mathrm{Wd}=$ $0.0075(\% \mathrm{RC})^{2}-0.0785$ (\% RC) + 1.8225 with a correlation coefficient: $\mathrm{R}^{2}=0.9948$. And the dry density of the mortar varies according to the rubber content according to the expression: $\mathrm{Dd}=-0.0025(\% \mathrm{RC})^{2}$ $0.0165(\% \mathrm{RC})+1.5825$ with a correlation coefficient: $\mathrm{R}^{2}=0.9453$.

It is worth noting that reductions in water absorption during total immersion are approximately $18.92 \%$ to $19.25 \%$ for mortar based on dune sand and with the substitution of rubber content of $10 \%$ and $20 \%$ respectively, as shown in (Figure 9). These results are in accordance with the findings of various authors for the incorporation of rubber aggregates in cement matrix and with zero absorption of rubbers [15-16] cited by Boukour [14]. This is surely due to a probable decrease in the porosity of these mortars. On the other hand, there was a return in the decrease in absorption of the order of $7.18 \%$ for the DS-based mortar and with $30 \%$ of RC substitutions, different from the result found by Boukour [14] 


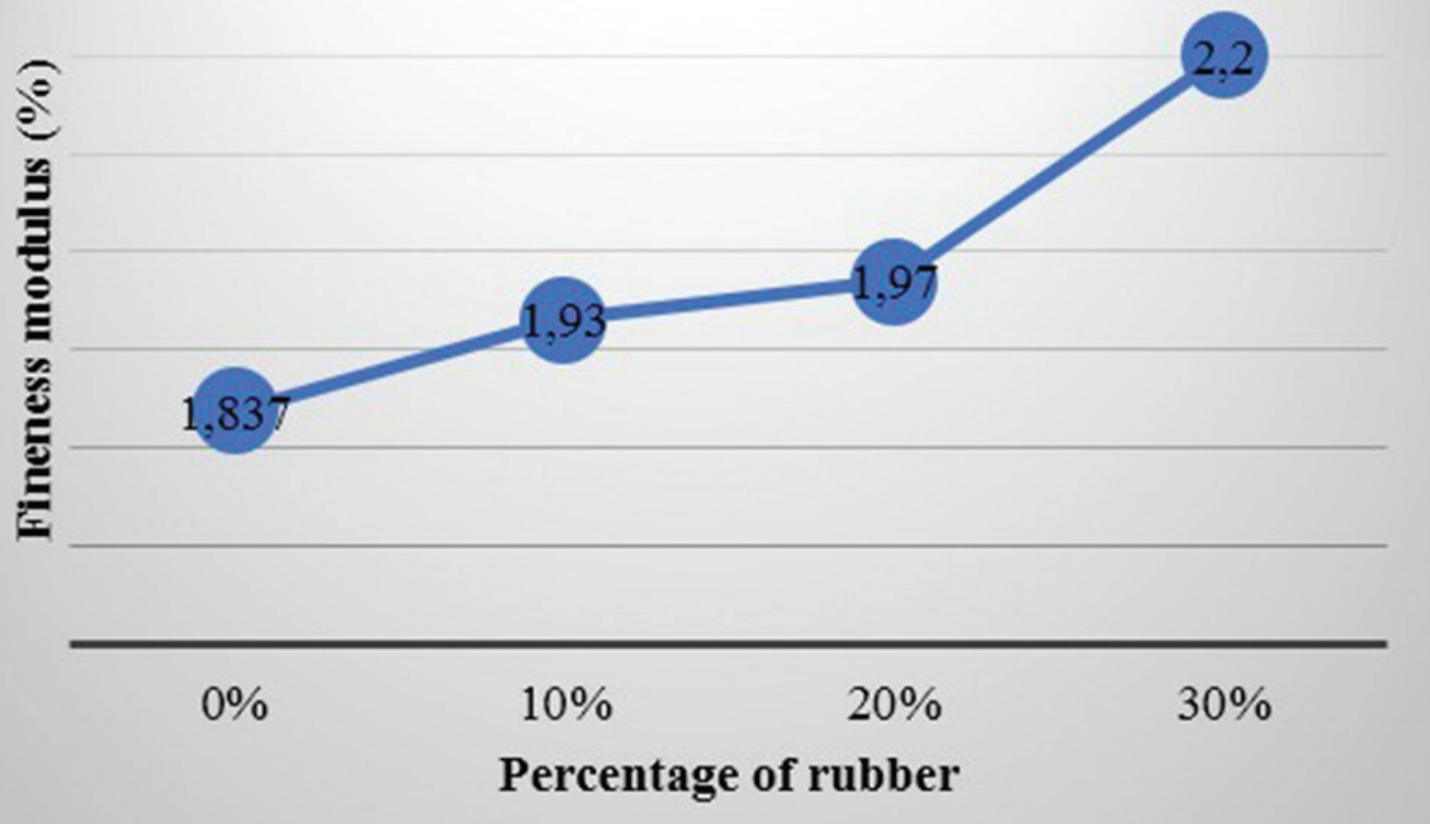

Figure 7: Evolution of fineness modulus as a function of rubber content.

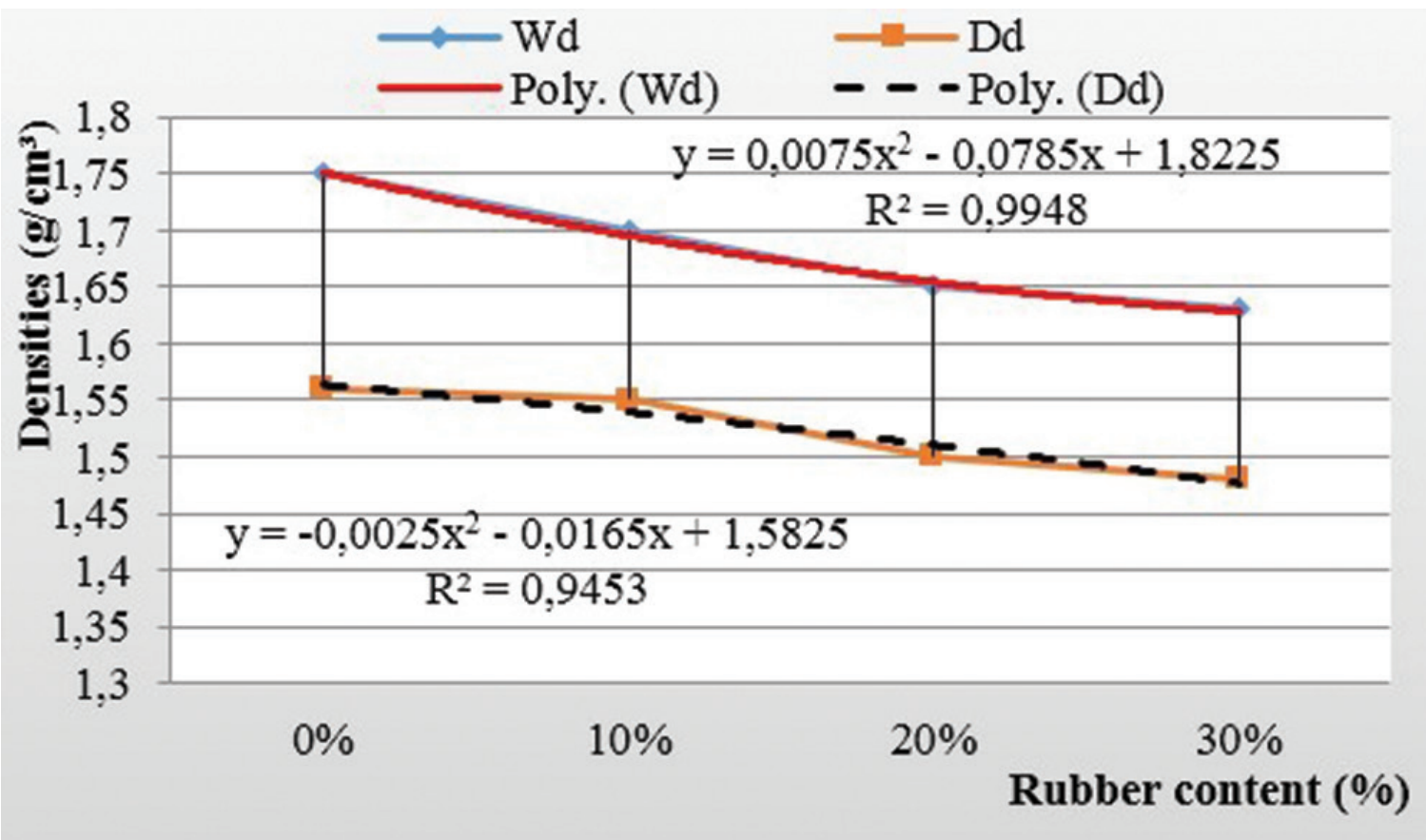

Figure 8: Evolution of density as a function of rubber content.

for this percentage of substitution. Our result could be related to the pores generated by this amount of RCs due to their non-polar natures and their smaller size compared to RAs (rubber aggregates), which tend to trap surface air. The air trapped in this mortar makes the mortar more porous, therefore more permeable and more water-absorbent. 


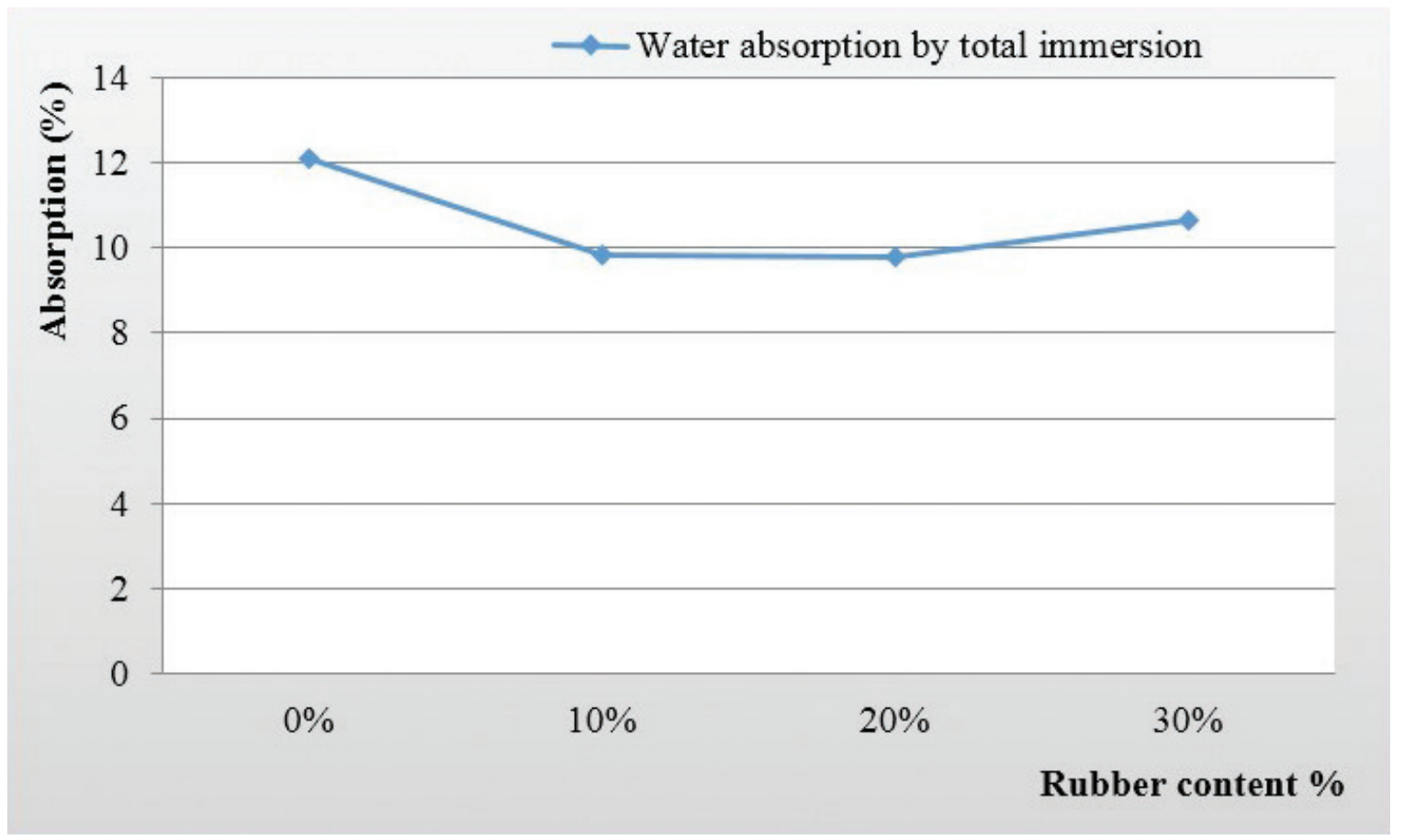

Figure 9: Evolution of absorption by total immersion depending on the rubber content

The decrease in porosity (Figure 10) reached $19.35 \%$ and $22.11 \%$ respectively for sand mortars with $10 \%$ and $20 \%$ substitutions of DS by RC, which confirms the findings noted above concerning the possibility of a decrease in DS porosity, especially at $10 \%$ of substitutions of DS by RC. This is contrary to the results of other authors, which indicate that the occluded air entrained by the RA during mixing is a factor favouring the increase in porosity [17-19]. At $30 \%$ substitutions of DS by $\mathrm{RC}$, the return is also noticed (5.42\%). Note that other authors [20-21] suggest that the hydrophobic nature of RA is responsible for trapping air bubbles, which contributes to the lightening of RA composites.

\section{Effect of rubber on the mechanical properties of the mortar}

It can be seen from Figure 11 that the substitution of dune sand by rubber content reduces resistance, while the tensile strength decreases slightly, usually on the order of $9.51 \%$ to $13.89 \%$ with substitution of $10 \%$ and $20 \%$ respectively; reduction in tensile strength is very significant at $30 \%$ substitution (38.57\%). On the other hand, for compressive strength the decreases are more than $30 \%$ for the three substitutions $(10 \%, 20 \%$, and $30 \%)$ on the order of $30.44 \%, 34.63 \%$, and $47.15 \%$, respectively. This loss of mechanical performance, according to Guelmine et al. [10] is mainly linked to the poor adhesion of the rubber particles to the cement matrix. Most remarkable are the decreases in both mechanical resistances at $30 \%$ substitution, which can lead us to limit the percentage of substitution to less than $30 \%$. But despite that, this loss remains less than that found by Boukour [14].

\section{Effect of rubber on the relationship between the mechanical properties of the mortar}

The relationships between strengths (compressive and tensile) can be influenced by the substitution of DS by RC. It has been observed through the results of these properties that they can present different values. In this part of the work, we explore the effect of rubber on these relationships, between compressive strengths and tensile strengths (Figure 12). These relations between properties are also situated in relation to those given by the regulations Eurocode EC2 [22] and the Unified Document DTU [23]. 


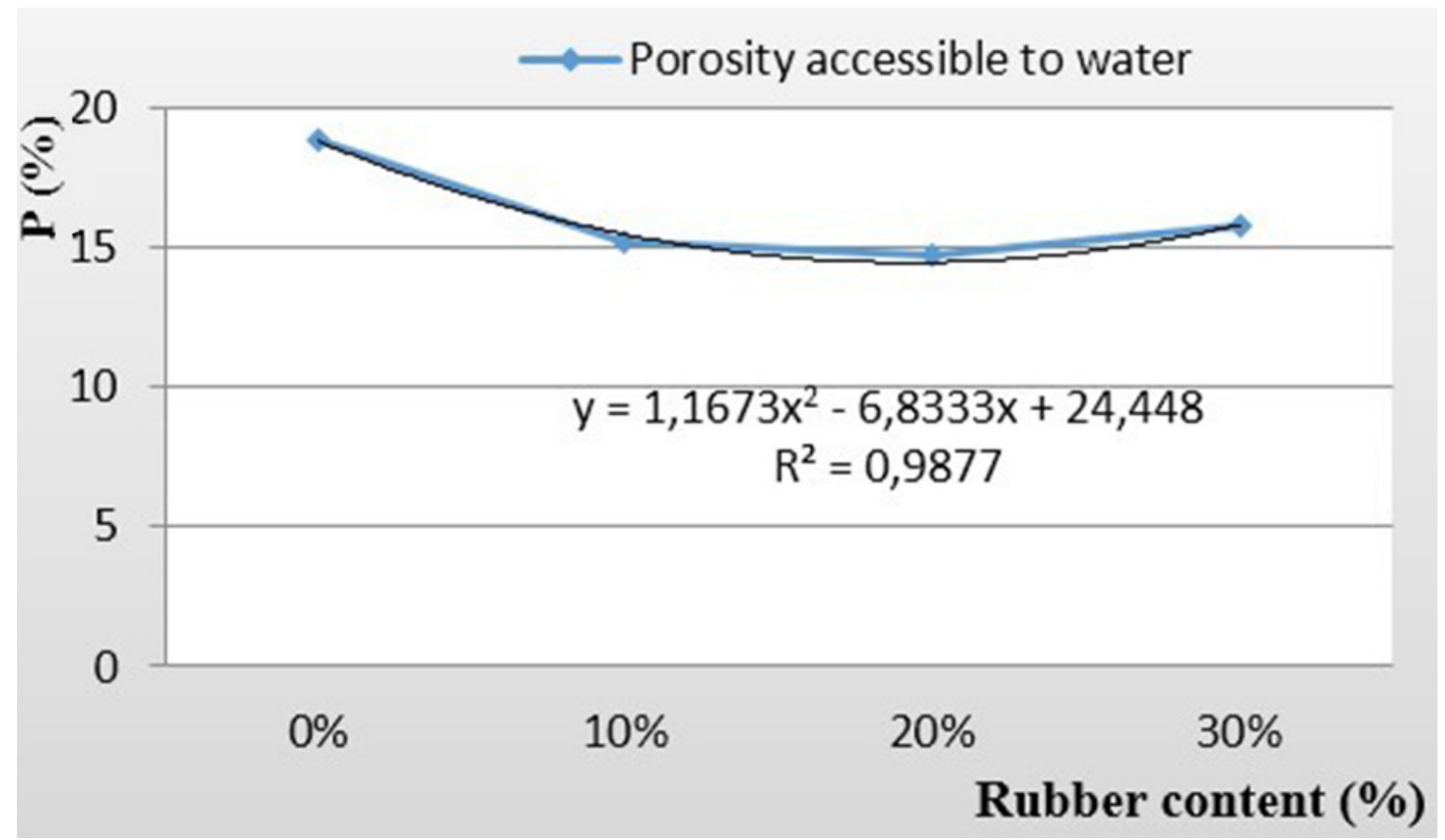

Figure 10: Evolution of porosity accessible to water as a function of rubber content.

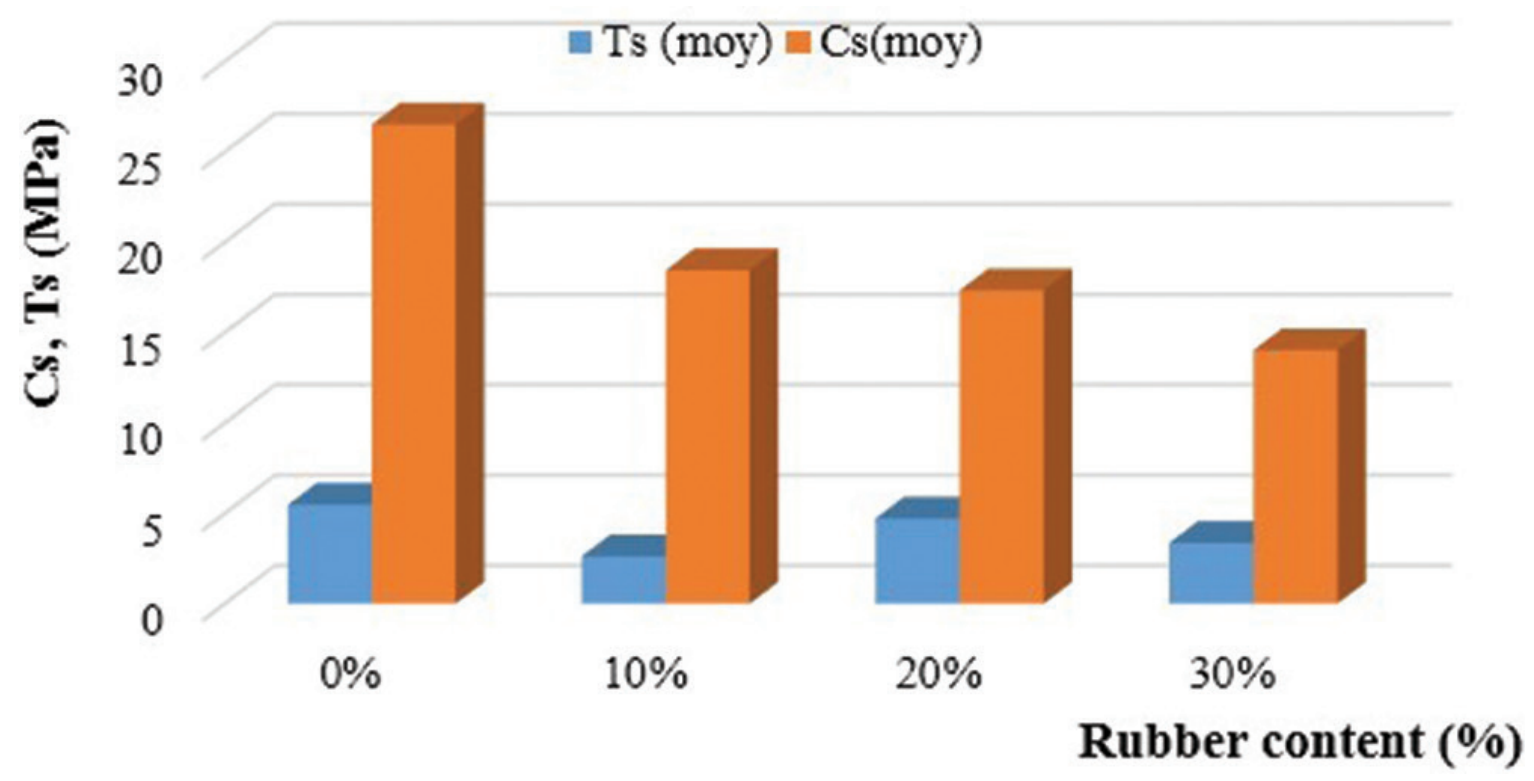

Figure 11: Evolution of the compressive and tensile strength as a function of the rubber content.

Relations between compressive strengths and tensile strengths

The preceding curves (Figure 12) show the Ts-Cs (Tensile strength and Compressive strength) relationships for rubberized sand mortars at $0 \%, 10 \%, 20 \%, 30 \%$ of RC. We notice that the difference between the regulatory curves and the experimental curve of the mortars studied is also important despite the reverse direction of the evolution (decrease depending on the rubber content) with a very acceptable regression quality Rt-Rc $\left(\mathrm{R}^{2}=0.9988\right)$.

The Ts-Cs relation of rubberized sand mortars at $0 \%, 10 \%, 20 \%, 30 \%$ of RC always gives 


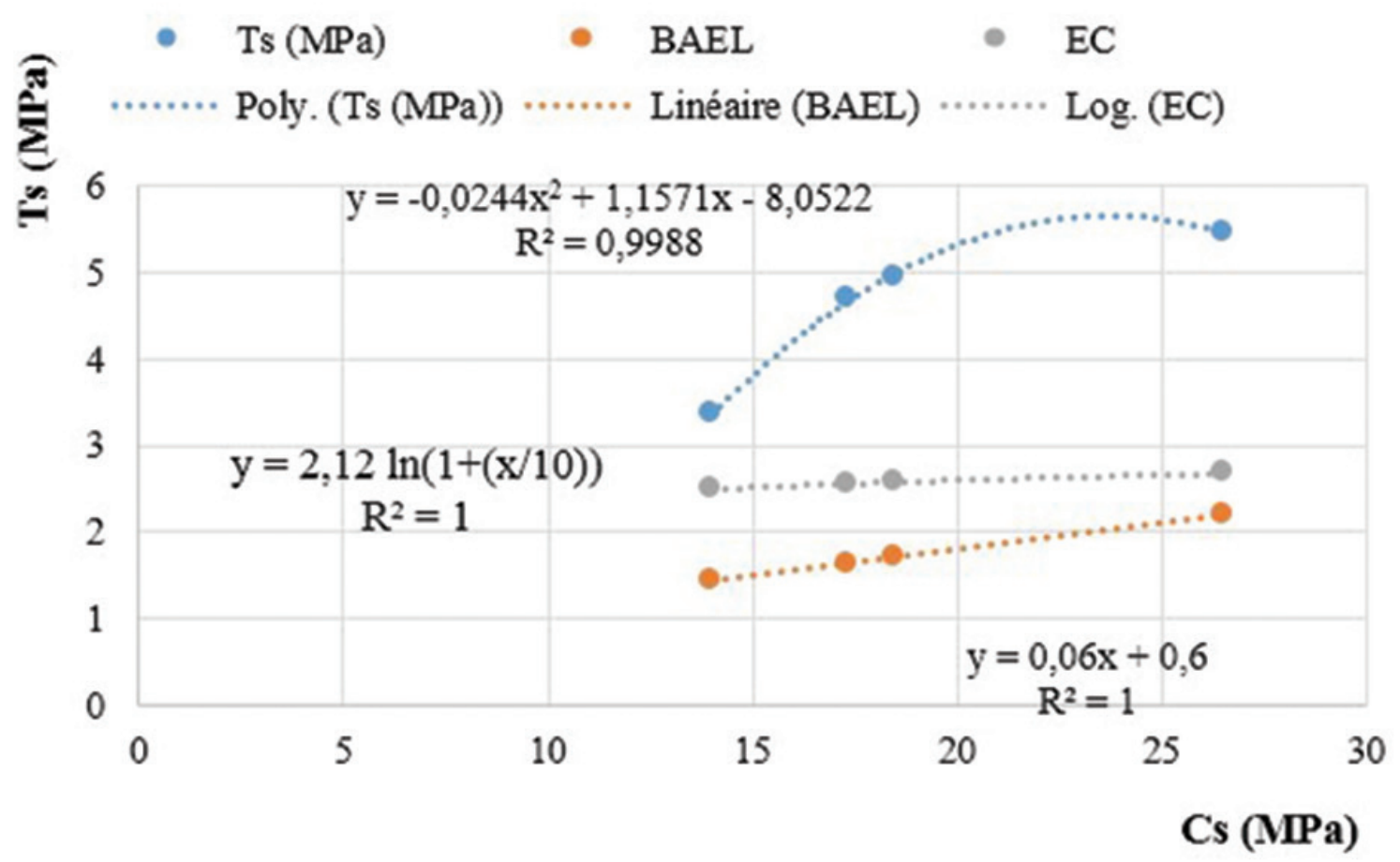

Figure 12: Relations between compressive strengths and tensile strengths.

overestimated values, but of course not at the same pace as those of the regulations (polygonal relation) these values are influenced by the presence of dune sand in the compositions of the mortars.

It can be seen that the Ts-Cs relationships are influenced by the percentage of dune sand substitution by RC.

\section{Conclusions}

The correction of the grain size of the DS is possible by the RC. This is clearly verified by the fineness modulus, which marked a jump between the two ends of the fine aggregate interval. This improvement is noticed especially at $30 \%$ substitution.

Rehabilitation work and the lightening of structures are based mainly on the values of the densities of the construction materials. The decrease in the values of the latter is noticed for the three substitutions $(10 \%, 20 \%$, and $30 \%)$ but is less important than those found by several other authors. They follow polygonal functions of order 2 with correlation coefficients very close to 1 .

A positive effect for absorption by total immersion is found up to $20 \%$ substitution of DS by RC. On the other hand, at $30 \%$ of substitutions the absorption increased.

The effect of the substitution of DS by RC on the porosity of the mortars is the same as that of the absorption, with different values (decrease in up to $20 \%$ of substitution and an increase in up to $30 \%$ of substitution).

The percentage of substitution of DS by RC can be limited to less than $30 \%$ because of its detrimental effect on the two mechanical resistances.

The relation which connects the two mechanical resistances (traction and compression) is influenced by the percentage of substitution of dune sand by RC. It presents estimates greater than those of the normative documents, by following a polygonal function of the order 2 with a correlation coefficient very close to 1 .

\section{Acknowledgements}

The authors thank the LGCH research laboratory at the University 8 May 1945 (Guelma) and the pedagogical laboratory of the civil and hydraulic engineering department (Guelma) for their technical support during the experimental work. 


\section{References}

[1] Bouaziz, A., Hamzaoui, R., Rezigue, S., Bennabi, A. (2013): Valorization of dune sand in formulations of mortars and concrete. In: 31st AUGC Meetings, E.N.S. Cachan, May 29 to 31, pp.1-11.

[2] Boudaouad, Z., Breysse, D. (2002): Study of the effects of co-grinding of a sand and a clinker on the properties of concrete. Materials and Structures, 5 (35), pp. 310-316, DOI: https://dx.doi. org/10.1617/13734.

[3] Bilhout, H., Dilude, P. (1994): Sand concrete. Paris, Jouve, p. 11.

[4] Cisse, K., Lauuerbe, M., Gaye, A., Diene, M. (1999): Characterization of compacted road sand concretes: application to the case of Senegal. Materials and Construction, 32 (216), pp. 151-157.

[5] Cissé, K., Lauuerbe, M. (2000): Mechanical characterization of filler sand concrete with rice husk ashes addition: study applied to Senegal. Cement and Concrete Research, 30 (1), pp. 13-18, DOI: https:// doi.org/10.1016/S0008-8846(99)00182-9

[6] Benaiss, A., Morlier, P., Tram, V. (1992): Concrete sand, a non-cracking material. Francis Jeanson National School of Public Works, Algeria equipment, (materials) pp. 7-10.

[7] Tafraoui, A. (2009): Contribution to the recovery of sand from the western erg dunes (Algeria). Application to new concretes, $\mathrm{PhD}$ thesis, University of Toulouse, $223 \mathrm{p}$.

[8] Belkhiri, H., Derragui, A. (2016): Contribution to the study of the mechanical behavior of dune sand and fine siliceous mortar. Master's thesis, Geotechnics \& Materials: Ziane Achour University of Djelfa, 74 p.

[9] Menadi, S., Benazzouk, A., Douzane, O., Merzoud Mohamed, M., Habita, F., Langlet, T. (2013): Study of the feasibility of a composite with a cement matrix reinforced with jute fibers. Synthesis: Revue Science Technology syntheses, (27), pp. 40-49.

[10] Guelmine, L., Hadjab, H., Benazzouk, A. (2018): Effect of recycled rubber granulates on used tires on the physical and mechanical properties of cement mortar. In: International Civil Engineering Seminar, "IACS".

[11] Ho Anh Cuong, M. (2010): Optimization of the composition and characterization of a concrete incorporating aggregates from the grinding of used tires: Application to large surface elements. $\mathrm{PhD}$ thesis, University of Toulouse, $250 \mathrm{p}$.
[12] Hamlaoui, C.A., Moussaoui, H. (2019): Valorization of rubber waste from tires and glass waste in sand concrete. Master's thesis: Materials in Civil Engineering, University Akli Mohand Oulhadjde Bouira. 139 p.

[13] Benazzouk, A., Douzane, O., Quéneudec, M. (2006): Recovery of rubber waste in construction materials: case of a cellular cementitious composite. dechets-sciences-techniques, 41 (1), pp. 30-35, DOI: 10.4267/dechets-sciences-techniques.1762

[14] Boukour, S. (2017): Physico-mechanical characteristics and durability of cement eco-composites based on rubber aggregates from used tires, $\mathrm{PhD}$ thesis, University of 8 May, 1945 Guelma, 237 p.

[15] Nehdi, M., Khan, A. (2001): Cementitious composites containing recycled tire rubber: an overview of engineering properties and potential applications. Cement, Concrete and Aggregates, 23(1), pp. 3-10, DOI: https://doi.org/10.1520/CCA10519J

[16] Price, W., Smith, E.D. (2006): Waste tire recycling: environmental benefits and commercial challenges. International Journal of Environmental Technology and Management, 6(3/4), pp. 362-374.

[17] Benazzouk, A., Douzane, O., Langlet, T., Mezzeb, K., Roucoult, J.M., Quéneudec, M. (2007): Physicomechanical properties and water absorption of cement composite containing shredded rubber wastes. Cement Concrete Composite, 29 (10), pp. 732-740, DOI: https://doi.org/10.1016/j. cemconcomp.2007.07.001.

[18] Fadiel, A., Al Rifaie, F., Abu-Lebdeh, T., Fini, E. (2014): Use of crumb rubber to improve thermal efficiency of cement-based materials. American Journal of Engineering and Applied Sciences, 7 (1), pp. 1-11, DOI: https://doi.org/10.3844/ ajeassp.2014.1.11.

[19] Eiras, J.N., Segovia, F., Borrachero, M.V., Monzó, J., Bonilla, M., Payá, J. (2014): Physical and mechanical properties of foamed Portland cement composite containing crumb rubber from worn tires. Materials and Design, 59, pp. 550-557, DOI: http://dx.doi. org/10.1016/j.matdes.2014.03.021.

[20] Hernandez-Olivares, F., Barluenga, G. (2004): Fire performance of recycled rubber-filled highstrength concrete. Cement and Concrete Research, 34(1), pp. 109-117, DOI: https://doi.org/10.1016/ S0008-8846(03)00253-9.

[21] Siddique, R., Naik, T.R. (2004): Properties of concrete containing scrap-tire rubber-an overview. Waste 
Management, 24(6), pp. 563-569. DOI: https://doi. org/10.1016/j.wasman.2004.01.006.

[22] EUROCODE 2 (ENV 1992-1-2): Design of concrete structures, Part 1-2: General rules - calculation of fire behavior. February 2001.
[23] BAEL 91 rules (DTU P 18-702) (revised February 99, 2000) Technical rules for the design and calculation of reinforced concrete structures and structures using the limit states method Fascicle 62, title 1 of the CCTG - Works section 1: reinforced concrete 1. 